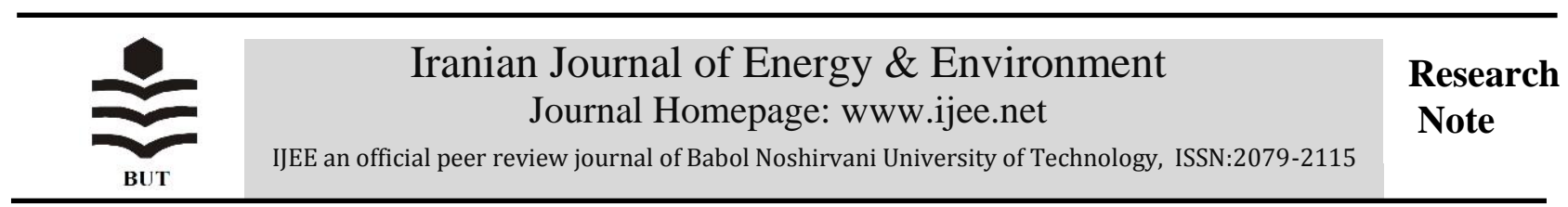

\title{
Experimental Study of a Double Glazed Solar Air Collector
}

\author{
F. Chabane ${ }^{1,2 *}$ and E. SEKSEFF ${ }^{1}$
}

${ }^{1}$ Department of Mechanical Engineering, Faculty of Technology, University of Biskra 07000, Algeria 2 Laboratoire de Génie Mécanique (LGM), Faculty of Technology, University of Biskra 07000, Algeria

\section{$P A P E R \quad I N F O$}

Paper history:

Received 18 Augest 2018

Accepted in revised form 21 October 2018

\section{Keywords:}

Double-glazed

Solar air collector

Efficiency

Mass flow rate

thermal losses

\section{$A \quad B \quad S T R$ R A $C$ C}

Our work focused on an experimental study of a double-glazed solar air collector in the BISKRA site. The main objective of our work was to minimize thermal losses forward. The experimental model used is based on addition of second glass and increase in distance between the two panes. The study was carried out for the comparison between the average absorber temperature, glass and the outlet temperature and the efficiency for the single-pane and double-pane solar air collector with variable distance $(1,2$ and $3 \mathrm{~cm})$. Correspond to the three flow rates used. Experimental results showed that the addition of second pane is effective in minimizing forward thermal losses for a solar air collector. The obtained results from the experimental readings showed that the minimization of thermal losses forward is a very important factor for improving the performance of a solar collector. Experimental results showed that the addition of second glazes is effective in minimizing forward thermal losses for a solar air collector.

doi: $10.5829 /$ ijee.2018.09.03.02

\section{INTRODUCTION}

Renewable energies experienced a first phase of development during the oil shocks in 1973.

Among the renewable energies, we quote the solar energy as "clean energy". The exploitation techniques of this resource have seen in recent years a remarkable mutation involving a state-of-the-art technology, especially its availability over a large part of the globe and the absence of any risk of exhaustion known from fossil sources. The solar air collector was the first work initiated in this area. The low efficiency of this type of sensor has led researchers to investigate other ways to improve performance and minimize heat loss and increase efficiency. In this article we shall present some work done in the field of solar. In order to minimize thermal losses to the front of the absorber, Benyelles, et al. [1] have minimized the forward thermal losses proposed to place a "silica air-gel" insulation at absorber; they have chosen the silica air-gel due to its properties; it is a low density solid material ranging from 80 to 270 $\mathrm{kg} / \mathrm{m} 3$. Transparent, porous (35 to $90 \%$ porosity). Its refractive index is between 1.2 to 1.5 . For a thickness of about $20 \mathrm{~mm}$ the normal solar transmission is $90 \%$. Its thermal conductivity is of the order of $0.02 \mathrm{~W} / \mathrm{m} . \mathrm{K}$.

The influence of some parameters on the loss coefficient thermal forward sensor was investigated. Benkhelifa [2] conducted a theoretical study in which it presents model which makes it possible to calculate these thermal losses. The balance sheet equations were solved by an iterative method. The obtained model gave results in agreement with those resulting from the empirical relations encountered in the literature.

Njomo et al. [3] carried out an experimental study of a solar air collector with an analysis of the influence of various parameters, such as the heat transfer fluid inlet temperature, the mass flow rate of this fluid and the distance between the absorber and the combined system of covers, on the thermal behavior of the collector.

El-Sebaii, et al. [4] carried out a theoretical and experimental study on an air-heater solar collector equipped with flat and corrugated $\mathrm{V}$-shaped absorbers. The theoretical results obtained were compared with experimental ones. This is the evaluation of the thermal losses from the tests on the outlet temperature for two cases of configurations, manifold with flat absorbers and $\mathrm{V}$ - undulated. They concluded a good agreement between the measured and the theoretical performances. They have also shown that a double passage manifold with a vcorrugated plate is $11-14 \%$ more efficient than a doublepass manifold with a flat plate.

Kiatsiriroat, et al. [5] experimentally studied the heat transfer enhancement of a flat plate solar air heater using an electric field. The aim of the study was to investigate the effect of electrode spacing and Reynolds number on

* Corresponding author: Chabane Foud

E-mail: fouedmeca@ hotmail.fr 
the performance of the solar air heater. The experiments were conducted with and without electric field under steady state conditions with a solar radiation range between $840-1100 \mathrm{~W} / \mathrm{m}^{2}$. It was concluded that the electric field significantly enhanced the heat transfer rate at low Reynolds numbers. Othman, et al. [6] theoretically and experimentally studied a hybrid photovoltaicthermal (PV/T) solar air heater. The solar air heater was a double pass system with monocrystalline silicon cells pasted on the absorber plate with fins attached on the other side of the absorber plate in the second channel. The comparisons between theoretical and experimental studies were in a good agreement with each other.

Gao, et al. [7] experimentally analyzed the thermal performance of cross-corrugated and flat-plate solar air heaters. Both absorbing and bottom plates of the analyzed solar air heaters were cross-corrugated to enhance the turbulence and consequently the heat transfer rate inside the air flow channel. Three solar air heaters with different designs were investigated in their study.

In addition, the effects of selective coatings on the solar air heaters were investigated. It was found that the selective coatings increase thermal performance of the heaters and its use was strongly recommended for practical applications.

Enibe [8] produced a single pass flat plate solar air heater integrated with phase change material (PCM) heat storage system. He used paraffin type prepared in modules. It was found that for solar collectors with storage, when the cumulative efficiency includes the time integral of energy it was a more useful measurement of performance than the instantaneous efficiency. The peak temperature rise of the heated air was about $15 \mathrm{~K}$, while peak cumulative useful efficiency was about $50 \%$.

Koyuncu [9] experimentally and theoretically studied the performance of various designs of solar air heaters for crop drying applications. He aimed to determine a cheap an easily manufactured and a high efficiency solar air collector for low temperature crop drying applications.

Karim, et al. [10] conducted an experimental study to evaluate the thermal performances of three types of solar air heaters; a simple flat plate, finned and V-corrugated solar air heaters. The aim of their study was to achieve the most efficient design of solar air collector suitable for solar drying. Three types of collectors were designed, constructed and tested.

Kurtbas, et al. [11] analyzed the efficiency and exergy of a solar air heater. In order to investigate the effect of flow line dimensions of a solar collector on its performance, an absorber was designed with four different plates. The efficiency of the collector significantly depends on the surface geometry of the collector. The pressure loss and the heat transfer increased as the roughness of the absorber surface increases

Togrul, et al. [12], studied the performance of a solar air heater with a cylindrical absorber which is fixed to the center of a conical concentrator. They aimed to enhance the air outlet temperature of solar air heater when compared to a flat plate collector.

It was concluded that, with a conical concentrator, the efficiency and air temperature were increased by $12 \%$ and $150^{\circ} \mathrm{C}$, respectively.

\section{MATERIAL AND METHOD}

In this work, we designed a flat air solar collector with double glazing. Our project is an experimental study of the Biskra site, and the essential goal minimized thermal losses to the front. For this purpose, single-glaze, solar air collector measurements should be compared with the variable-range, dual-pane solar collector measurements for multiple flow rates.

\section{Characteristic of the measurement site}

Tests performed in a period established in the month of February to April 2016, characterized by its Saharan climate. The Biskra site is located at latitude $34^{\circ} 38$ 'N and longitude $5^{\circ} 44^{\prime} \mathrm{E}$. The tests were carried out for clear days free of disturbance.

\section{Description of the studied solar collector (Effective area):}

Length of the collector: $67 \mathrm{~cm}$

-Width: $46 \mathrm{~cm}$

-Absorber flat galvanized steel, painted mat shipments, equal thickness $0.4 \mathrm{~cm}$

-Inclination of the sensors $\beta=37$

-The gap, absorber - glazed equal $40 \mathrm{~mm}$

-The flow is below the absorber

-The coolant is air thickness.

-The insulation is expanded polystyrene at $20 \mathrm{~mm}$

- A transparent plexiglass cover $3 \mathrm{~mm}$ thick

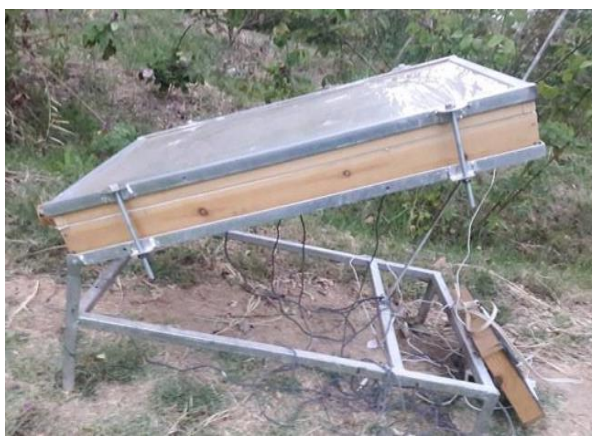

Figure. 1. Solar collector realizes for the experimental study 


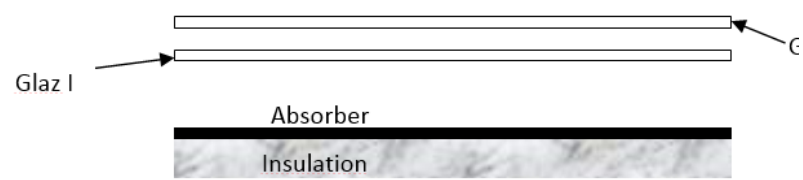

Figure. 2. Illustration of the double-glazed

The first test uses the collector to a single glass:

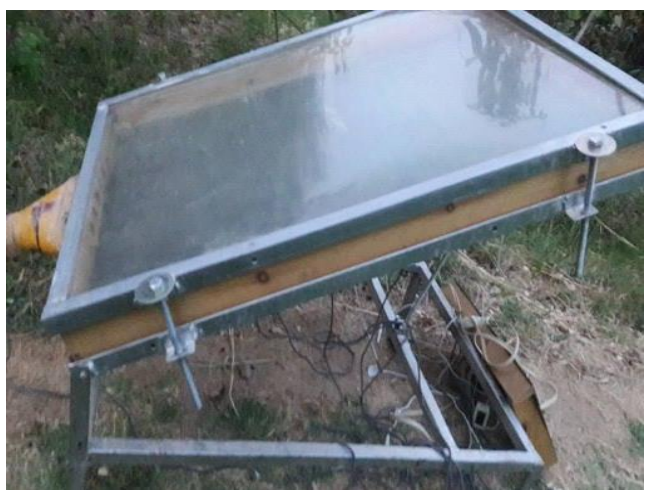

Figure 3. Single-glaze of solar collector

This figure shows a south-facing single-pane solar collector

2. The second test uses the double-glazed collector with a distance of $1 \mathrm{~cm}$

This figure shows how placed the second glass of our collector. The separation between the two panes with a wooden frame its height of $1 \mathrm{~cm}$.

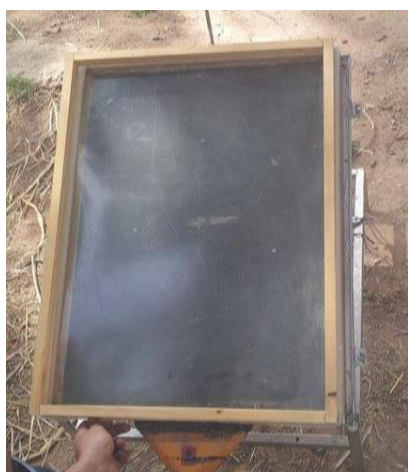

Figure 4. Solar collector with double glazing at a distance of $1 \mathrm{~cm}$

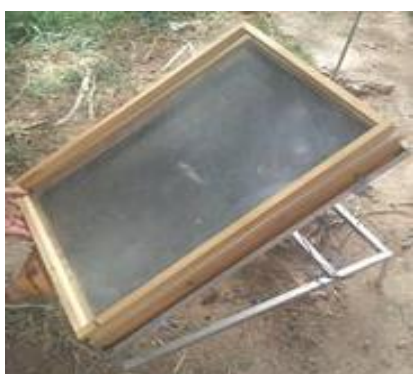

Figure 5. Solar collector with double glazing at a distance of $2 \mathrm{~cm}$
The same procedure of flat solar collector has double glass of distance of $1 \mathrm{~cm}$ but in this case we increased the distance between the two windows to $2 \mathrm{~cm}$

4. The fourth test increased the distance to $3 \mathrm{~cm}$ :

It is noted that the air returns to these three uses holes successively to avoid dead zones.

This figure represents the output of hot air

-Each test the essential parameters are the radiation measurements, the exit and inlet temperatures, the absorber and the window temperatures.

-The same procedure for other flows.

-Our test, measurement made successively.

\section{Measuring instruments:}

The measurement companion was carried out in the Technological Hall of the Department of Mechanical Engineering of the University of Biskra and at the roof level of our house during 3 months for 3 modes of air circulation ( 3 flows) in the sensor alone glass and double glass. In order to be able to minimize thermal losses forward, during each measurement day tests are taken between 9am and 4pm. In order to carry out the

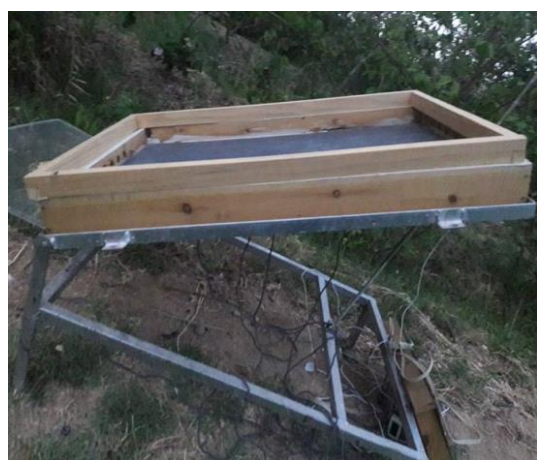

Figure 6. Solar collector with double glazing at a distance of $3 \mathrm{~cm}$

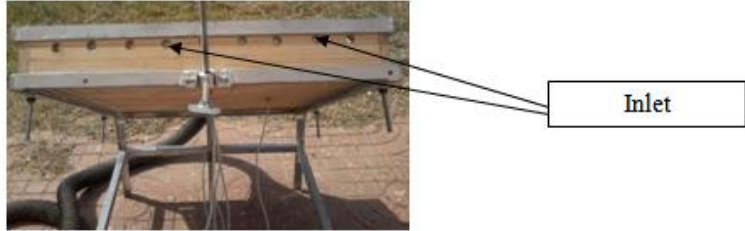

Figure 7. The air inlet holes

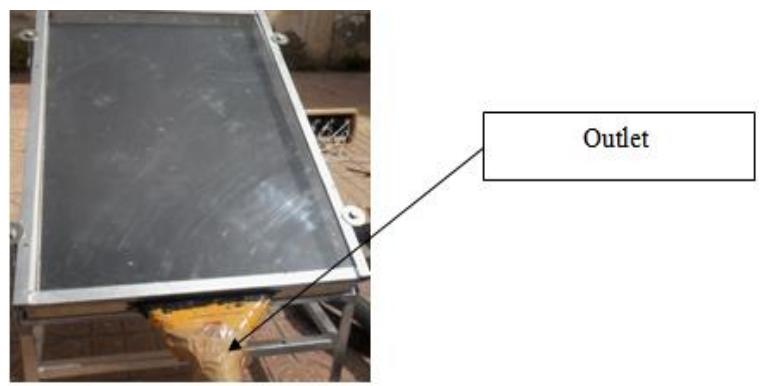

Figure 8. Hot air outlet 
experiment, ten thermocouples were placed on the system, distributed as follows :

- thermocouples at the sensor inlet and outlet

- thermocouples at the Absorbent plate

- thermocouples on the glass.

\section{Pyranometer}

The instrument used to measure global solar radiation [W $/ \mathrm{m}^{2}$ ] PYRANOMETER type VOLTCRAFT PL-110SM.

\section{Anemometer with fins}

Used to measure the coolant flow rate is made at the air outlet, the anemometer used in our study The thermoanemometer with propeller PCE -TA 30.

\section{Temperature measurement}

Temperature measurements at the inlet, outlet, the absorber and windows are made using probes such as: DIGITAL THERMOMETER TPM-10. The acquisition of temperatures is made through a set of 10 probes, 2 probes for the input and output of the sensor, 4 probes for the absorber and 4 probes for the glass.

\section{RESULTS AND DISCUSSION}

The main objective of our study is to minimize thermal losses forward. We try to compare the results of the measurements made with those obtained from the tests of our experimental work. We present through the figures that follow the curves that translate the comparison between the single-glaze and double-glazes with variable distance. collector according to $\mathrm{m}=0.0025 \mathrm{~kg} / \mathrm{s}$

Fig. 9 describes the variation of the average temperature of the absorber as a function of the length according to $\mathrm{m}$ $=0.0025 \mathrm{~kg} / \mathrm{s}$. It has been found that the temperature of double-glazed takes optimal values, whereas the singleglass takes minimum values. We also note that the CSP curve has a double window distance $2 \mathrm{~cm}$ decreases due to the high wind speed during the measurement day compared to double glazes distance $2 \mathrm{~cm}$, also the solar collector curve has double glazes distance $3 \mathrm{~cm}$; because of solar radiation (type of sky is partial).

Figure10 shows the variation of the average absorber temperature as a function of the CSP length, according to

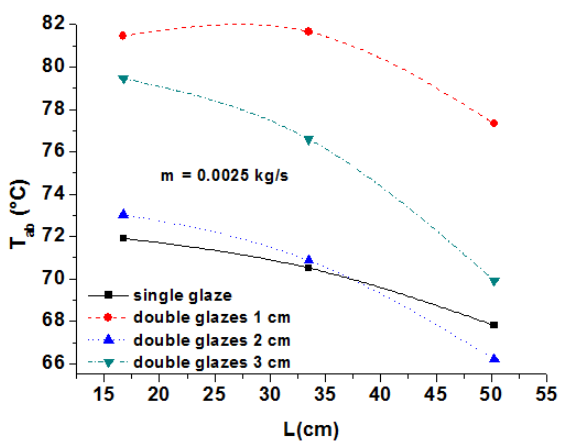

Figure 9. Variation of the temperature of the absorber according to the length of solar

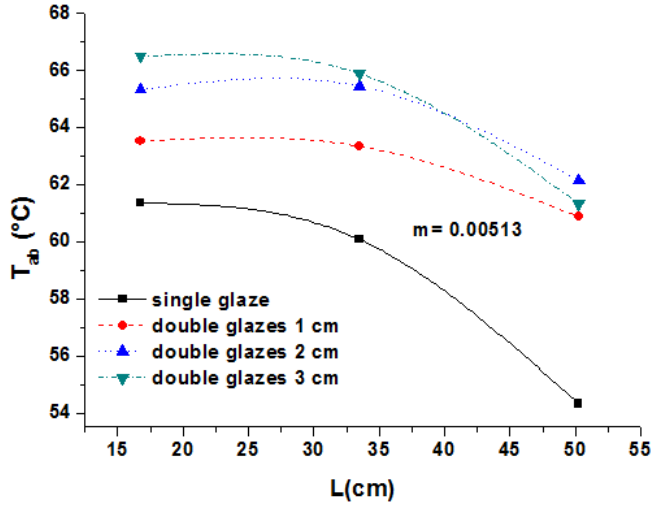

Figure 10. Variation of the temperature of the absorber according to the length of solar collector according to $\mathrm{m}=$ $0.00513 \mathrm{~kg} / \mathrm{s}$

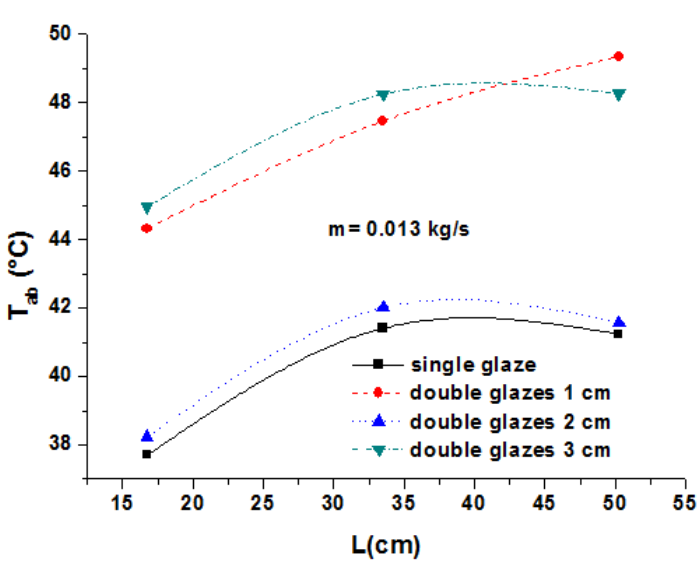

Figure 11. Variation of the temperature of the absorber according to the length of solar collector according to $\mathrm{m}=$ $0.0013 \mathrm{~kg} / \mathrm{s}$

$\mathrm{m}=0.00513 \mathrm{~kg} / \mathrm{s}$. These results are to be taken in the case of single-glaze and the case of double-glazes correspond the distance between the two cover glazes $(1,2$ and $3 \mathrm{~cm})$. The four curves are shown the situation of the probe on the absorbing plate. The maximum values of the temperature of the absorber between 66 and $67{ }^{\circ} \mathrm{C}$. It is observed that the increase of the temperature of the absorber in parallel with the increase in distance between the two glazes. We take into account that the temperature of double glazes at a distance of $2 \mathrm{~cm}$ decreases compared to the double glass at a distance of $1 \mathrm{~cm}$ and 3 $\mathrm{cm}$. In this case the temperature evolution of the absorber is disturbed in this day because of climatological conditions due to the high wind speed.

\section{CONCLUSIONS}

This work is an experimental contribution to the study of minimizing forward thermal losses on a solar air collector in the Biskra site. To minimize forward thermal losses the experimental model used is based on the addition of 
second pane and the increase in distance between the two panes. The study was carried out for the comparison between the average absorber temperature, glass and the outlet temperature and the efficiency for the singlewindow and double-glazed air-cooled solar collector with variable distance $(1,2$ and $3 \mathrm{~cm})$. Correspond to the three flow rates used. Experimental results showed that the addition of second glazes is effective in minimizing forward thermal losses for a solar air collector.

The results obtained from the experimental readings showed that the minimization of thermal losses forward is a very important factor for improving the performance of a solar collector.

\section{REFERENCES}

1. F. Benyelles, B. Benbadjia, B. Benyoucef et Z. Ziani, 2007' 'Comparaison entre un Capteur à Aérogel de Silice et d'autre Capteur Plans", 13iémes Journées Internationales de Thermique, Albi, France, 28-30 Aout

2. A.Benkhelifa, 1998, "Optimisation d'un Capteur Solaire Plan', Revue des Energies Renouvelables, Physique Energétique, pp.13-18.

3. D. Njomo, 1998, Etude théorique du comportement thermique d'un capteur solaire plan à air à couverture combinée plastique-vitre. Rev. Gén. Therm (Elsevier). 37. (973-980).

4. El-Sebaii A.A., S. Aboul-Enein, M.R.I. Ramadan, S.M. Shalaby, B.M. Moharram. 2011. Investigation of thermal performance of-double pass- flat and v- corrugated plate solar air heaters. Energy 36: 1076-1086.

5. Kiatsiriroat, T., W. Jiatrakul and A. Nuntaphan. 2007. experimental study on heat transfer enhancement in solar air heater by electric field. Heat Transfer Engineering 28:38-41.

6. Othman, M.Y., B. Yatim, K. Sopian and M.N.A. Bakar. 2006. Double Pass Photovoltaic-Thermal Solar Collector. Journal of Energy Engineering 132(3): 121-126.

7. Gao, W., W. Lin, T. Liu and C. Xia. 2007. Analytical and Experimental Studies on the Thermal Performance of Cross-Corrugated and Flat-Plate Solar Air Heaters. Applied Energy 84: 425-441.

8. Enibe, S.O. 2002. Performance of a Natural Circulation Solar Air Heating System with Phase Change Material Energy Storage. Renewable Energy 27: 69-86.

9. Koyuncu, T. 2006. Performance of Various Designs of Solar Air Heaters for Crop Drying Applications. Renewable Energy 31, no. 7, 1073-1088.

10. Karim, M.A. and M.N.A. Hawlader. 2004. Development of Solar Air Collectors for Drying Applications. Energy Conversation and Management 45:329-344.

11. Kurtbaş, I. and A. Durmus. 2004. Efficiency and Exergy Analysis of a New Novel Solar Air Heater. Renewable Energy 29: 1489-1501.

12. Togrul, I.T., D. Pehlivan and C. Akosman. 2004. Development and Testing of a Solar Air-Heater with Conical Concentrator. Renewable Energy 29:263-275.

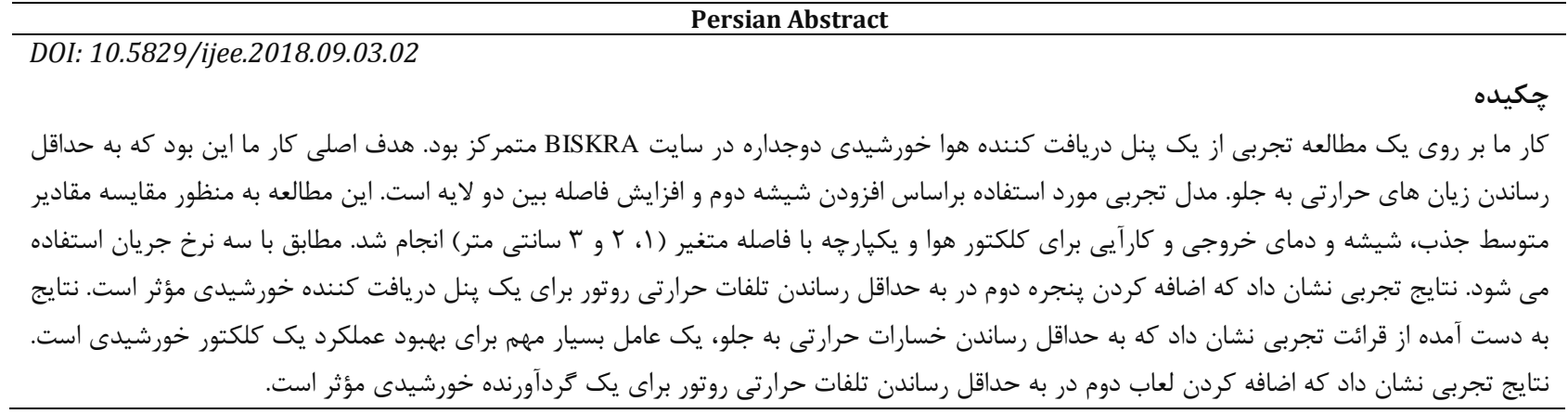

